\title{
Click-tambjamines as efficient and tunable bioactive anion transporters ${ }^{\dagger}$
}

Received 00th January 20xx, Accepted 00th January 20xx DOI: $10.1039 / \times 0 \times x 00000 x$

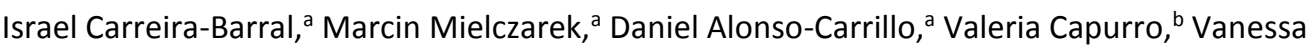 \\ Soto-Cerrato, ${ }^{\mathrm{c}}$ Ricardo Pérez Tomás, ${ }^{\mathrm{c}}$ Emanuela Caci, ${ }^{\mathrm{b}}$ María García-Valverde ${ }^{\mathrm{a}}$ and Roberto \\ Quesada*a
}

A novel class of transmembrane anion carriers, the clicktambjamines, display remarkable anionophoric activities in model liposomes and living cells. The versatility of this building block for the generation of molecular diversity offers promise to develop future drugs based on this design.

Facilitated anion transport is an emergent topic in supramolecular chemistry. ${ }^{1}$ The vast majority of natural ionophores are cation-selective, and some of them, polycyclic ethers for instance, are well-known antibiotics. ${ }^{2}$ On the other hand, the number of compounds known to facilitate the transmembrane transport of anions selectively, anionophores, is comparatively lower. ${ }^{3}$ Moreover, our knowledge about their biological activities is still limited. ${ }^{4}$ Potential applications of these compounds include development of anticancer chemotherapeutics, ${ }^{5}$ as a result of the toxicity derived from an altered homeostasis, and as channel replacement therapies in conditions related to defective anion transport across the cell membranes such as cystic fibrosis. ${ }^{6}$

Several designs of active anion transporters have been reported in the literature. ${ }^{7}$ They usually possess an array of hydrogen-bond donor groups, particularly $\mathrm{N}-\mathrm{H}$ fragments, which enable reversible anion coordination, thus forming a supramolecular complex capable of diffusing across the lipid membrane. Useful insights into anionophore design and function have been recently reported. ${ }^{8}$ Nevertheless, the discovery of easy-to-make, tunable molecular designs that allow extensive structure-activity relationships studies aimed at improving ADMET properties and modulating the balance

\footnotetext{
a. Departamento de Química, Universidad de Burgos, Burgos 09001, Spain. E-mail: rquesada@ubu.es

b. UOC Genetica Medica, IRCSS Istituto Giannina Gaslini, Genova, Italy.

c. Department of Pathology and Experimental Therapeutics, Faculty of Medicine, Universitat de Barcelona, Barcelona, Spain.

† Footnotes relating to the title and/or authors should appear here.

Electronic Supplementary Information (ESI) available: Experimental details, compound characterization data, anion transport and biological assays details.
} CCDC 1979548, 1979549 and 1979550. See DOI: 10.1039/x0xx00000x between transport activity and toxicity of these molecules is key to develop future drugs based on this concept.

Inspired by the structure of secondary metabolites tambjamines, ${ }^{9}$ we report here a new family of compounds in which one of the pyrrole groups of the 4-methoxy-2,2'-bipyrrole core characteristic of the natural product is replaced by a 1,2,3triazole ring (Fig. 1). We have coined the term "clicktambjamines" for the resulting compounds in which straightforward functionalisation in both the triazole ring and the imine moiety allows fast generation of molecular diversity.

Click-tambjamines 1-9 were synthesised by condensation of the appropriate amine (cyclopropyl-, cyclohexyl- or cyclooctylamine) and the corresponding triazole-containing aldehyde in boiling chloroform, employing acetic acid as catalyst. Copper-catalysed azide-alkyne Huisgen cycloaddition was used to generate the aldehyde precursors bearing a triazole ring with appended 4-chlorophenyl-, 4-trifluoromethylphenylor 4-pentafluorosulfanylphenyl-groups (see ESI for details). The compounds were isolated as their hydrochloric salts and fully characterised. Slow evaporation of solutions of compounds $\mathbf{1} \cdot \mathrm{HCl}, \mathbf{2} \cdot \mathrm{HCl}$ and $\mathbf{5} \cdot \mathrm{HCl}$ in $n$-butanol provided single crystals, suitable for X-ray diffraction analysis. In all cases the compounds form 1:1 adducts with the chloride anion. In the structures of $1 \cdot \mathrm{HCl}$ and $\mathbf{5} \cdot \mathrm{HCl}$, the three hydrogen-bond donor groups of the molecules are involved in the coordination of the chloride anion. In the case of that of $2 \cdot \mathbf{H C l}$ the $\mathrm{C}-\mathrm{H}$ fragment of the triazole ring is oriented to the opposite direction and interacts with a water molecule that is coordinated to the chloride anion of a neighbouring complex. The $\mathrm{N}-\mathrm{H}$ fragments of the three molecules form strong hydrogen bonds with the anion (the $\mathrm{N} \cdots \mathrm{Cl}$ distances fall in the range 3.05-3.25 $\AA$, and the $\mathrm{N}-\mathrm{H} \cdots \mathrm{Cl}$ angles are close to $\left.180^{\circ}\left(163.4-173.0^{\circ}\right)\right)$, whereas those in which the triazole $\mathrm{C}-\mathrm{H}$ fragment participates are weaker (the $\mathrm{C} \cdots \mathrm{Cl}$ distances and the $\mathrm{C}-\mathrm{H} \cdots \mathrm{Cl}$ angles are found between 3.59 and $3.62 \AA$ and 144.6 and $152.7^{\circ}$, respectively), in agreement with the lower polarisation of the $\mathrm{C}-\mathrm{H}$ group compared to that of the $\mathrm{N}-\mathrm{H}$ ones. ${ }^{10}$ The core of the three compounds was found to be essentially 

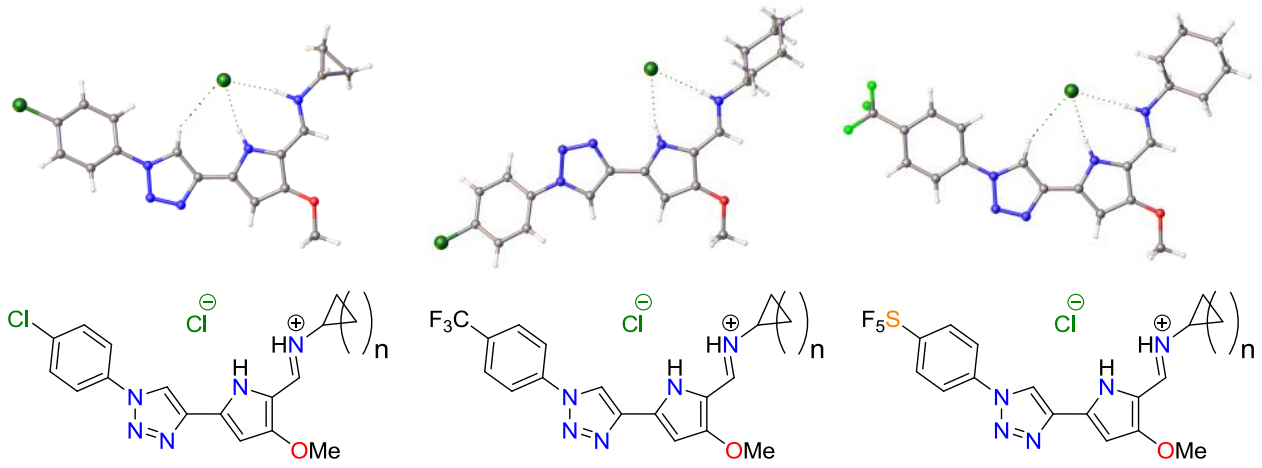

$1: n=1 ; 2: n=4 ; 3: n=6$

4: $n=1 ; 5: n=4 ; 6: n=6$

$7: n=1 ; 8: n=4 ; 9: n=6$

Fig. 1 Top: from left to right, solid state X-ray structures of compounds $\mathbf{1}, \mathbf{2}$ and $\mathbf{5}$ as their hydrochloric salts. Solvent molecules have been omitted for the sake of simplicity. In the case of $\mathbf{5}$, only one of the two molecules the asymmetric unit consists of is shown. Bottom: structures of the studied compounds.

flat, as the maximum mean deviation from planarity of the plane defined by the atoms of the triazole and pyrrole rings and the imine moiety is $0.034 \AA$.

The interaction of the protonated receptors with chloride, as well as with nitrate and bicarbonate, was also studied in solution by ${ }^{1} \mathrm{H}$ NMR spectroscopy. Titration experiments of the hydroperchloric salts of compounds 1-9 with the corresponding tetrabutylammonium salts in DMSO- $d_{6}$ were carried out. As an example, Fig. 2 displays the ${ }^{1} \mathrm{H}$ NMR stack plot obtained in the titration of $\mathbf{2} \cdot \mathrm{HClO}_{4}$ with $\mathrm{TBACl}$. Upon addition of chloride, the signals corresponding to the protons of the imine and pyrrole $\mathrm{N}-\mathrm{H}$ fragments as well as the triazole $\mathrm{C}-\mathrm{H}$ group undergo a progressive deshielding, in agreement with the interaction found in the solid state structures of $\mathbf{1} \cdot \mathrm{HCl}$ and $\mathbf{5} \cdot \mathrm{HCl}$. In order to quantify the binding, the association constants $K_{\mathrm{a}}$ were determined using the Bindfit software, ${ }^{11}$ by fitting the titration profiles to a 1:1 (LH:A) model, $L$ being the receptor and $A$ the anion (Table 1). The calculated values indicate that the adducts formed with chloride are more stable than those formed with nitrate, in line with the lower coordinating character of the latter. Bicarbonate induces deprotonation of the compounds and no $K_{\mathrm{a}}$ value could be ascertained in these conditions (see ESI).

Transmembrane anion transport was explored by means of two different techniques: potentiometry (ion-selective electrode, ISE) and emission spectroscopy. In all cases 1palmitoyl-2-oleoyl-sn-glycero-3-phosphocoline

(POPC) liposomes were employed. For the experiments involving the use of the chloride-selective electrode liposomes are filled with a sodium chloride buffered aqueous solution and they are suspended in an isotonic, chloride-free solution. The chloride efflux promoted by the studied compound is monitored over time and the resulting concentrations normalised by referring them to the total concentration of chloride in the liposomes, which is obtained after lysing them with a surfactant. The chloride efflux at 300 seconds for each concentration of compound employed is plotted against such concentrations and these data fitted with Hill equation. This fitting provides the $\mathrm{EC}_{50}$ parameter, representing the concentration of compound needed to induce a $50 \%$ release of chloride. ${ }^{12}$ This parameter is useful for comparing the relative potency of the anionophores; the lower the value of the $\mathrm{EC}_{50}$, the higher the potency of the transporter (Table 1). The transport activity was found to be dependent of the substitution of the imine. The cyclooctylcontaining compounds $\mathbf{3}, \mathbf{6}$ and $\mathbf{9}$ are the most active ones, closely followed by the cyclohexyl- derivatives $\mathbf{2}, \mathbf{5}$ and $\mathbf{8}$. The cyclopropyl- derivatives $\mathbf{1}, \mathbf{4}$ and $\mathbf{7}$ were found significantly less active (about one order of magnitude). The substituent of the aryl group was found to have little influence in the transport activity. Calculated $\mathrm{EC}_{50}$ values of the most active derivatives were found in the low nanomolar range, highlighting the extraordinary anionophoric activity of the most active click-

Table 1 Association constants $K_{\mathrm{a}}\left(\mathrm{M}^{-1}\right)$ for compounds 1-9 in their protonated forms with chloride and nitrate (added as tetrabutylammonium salts), determined from ${ }^{1} \mathrm{H}$ NMR titration experiments in DMSO- $d_{6}$ at $293 \mathrm{~K}$, and transport activities expressed as $\mathrm{EC}_{50}$ (nM).

\begin{tabular}{|c|c|c|c|c|}
\hline Comp. & $K_{\mathrm{a}}\left(\mathrm{Cl}^{-}\right)$ & $K_{\mathrm{a}}\left(\mathrm{NO}_{3}{ }^{-}\right)$ & $\begin{array}{c}\mathrm{EC}_{50} \\
\left(\mathrm{NO}_{3}{ }^{-} / \mathrm{Cl}^{-}\right)\end{array}$ & $\begin{array}{c}\mathrm{EC}_{50} \\
\left(\mathrm{HCO}_{3}{ }^{-} / \mathrm{Cl}^{-}\right)\end{array}$ \\
\hline $\mathbf{1}$ & $220 \pm 5$ & $11 \pm 1$ & $136 \pm 12$ & $2893 \pm 60$ \\
\hline $\mathbf{2}$ & $240 \pm 8$ & $4.5 \pm 0.4$ & $32.6 \pm 0.8$ & $130 \pm 7$ \\
\hline $\mathbf{3}$ & $397 \pm 23$ & $11 \pm 1$ & $10 \pm 1$ & $112 \pm 6$ \\
\hline $\mathbf{4}$ & $283 \pm 9$ & $18 \pm 2$ & $181 \pm 20$ & $2320 \pm 113$ \\
\hline $\mathbf{5}$ & $197 \pm 6$ & $10.3 \pm 0.9$ & $28 \pm 2$ & $137 \pm 37$ \\
\hline $\mathbf{6}$ & $281 \pm 7$ & $6.6 \pm 0.6$ & $11.0 \pm 0.4$ & $130 \pm 6$ \\
\hline $\mathbf{7}$ & $278 \pm 8$ & $11 \pm 1$ & $238 \pm 9$ & $3496 \pm 192$ \\
\hline $\mathbf{8}$ & $755 \pm 87$ & $12 \pm 1$ & $32 \pm 2$ & $236 \pm 15$ \\
\hline $\mathbf{9}$ & $255 \pm 8$ & $4.5 \pm 0.5$ & $21 \pm 2$ & $178 \pm 14$ \\
\hline
\end{tabular}




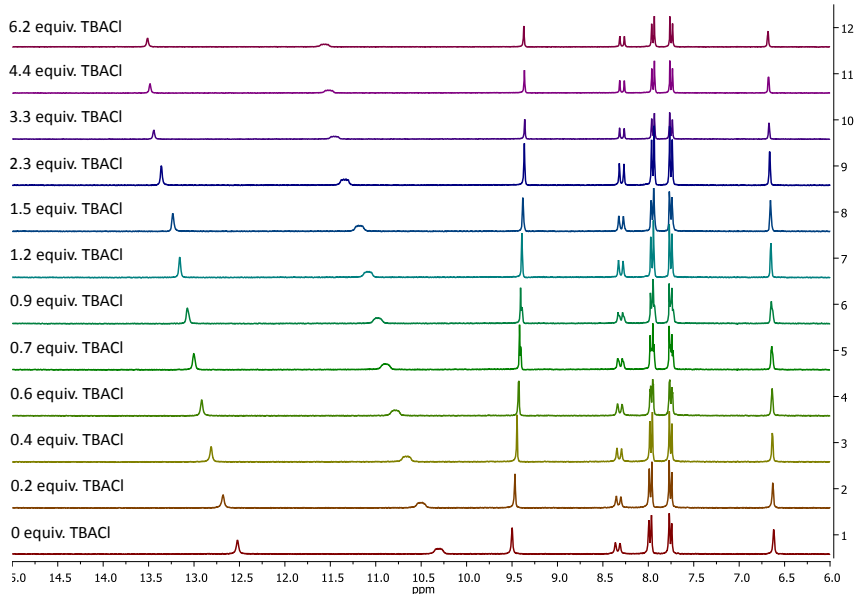

Fig. 2 Stack plot of partial ${ }^{1} \mathrm{H}$ NMR spectra of compound $2 \cdot \mathrm{HClO}_{4}$ in DMSO- $d_{6}$ with addition of increasing amounts of tetrabutylammonium chloride.

tambjamines. The observed trend in the transport activity result could be explained by the relative lipophilicity of the compounds, since 1, $\mathbf{4}$ and $\mathbf{7}$ are the less lipophilic derivatives of the nine studied (see calculated logP values, Table S2). ${ }^{13}$ The variation of the $\mathrm{EC}_{50}$ parameter when studying the chloride efflux in the presence of external nitrate, bicarbonate or sulfate is consistent with anion exchange as the main mechanism accounting for the transmembrane transport activity elicited by these compounds. Bicarbonate is less lipophilic than nitrate and therefore it is more difficult to extract into the lipid membrane; consequently, the $\mathrm{EC}_{50}$ values were found to be higher in the assays involving the chloride/bicarbonate exchange.

Emission spectroscopy experiments performed with carboxyfluorescein-loaded vesicles (see ESI for details) confirm that the anionophores do not form large non-selective pores in the lipid membrane, i.e., they do not behave as detergents. ${ }^{14}$ Additional assays with the $\mathrm{pH}$-sensitive fluorescent dye HPTS (see ESI for details) prove that these compounds efficiently dissipate $\mathrm{pH}$ gradients (Fig. 3), at concentrations as low as $0.0001 \% \mathrm{~mol}$ carrier to lipid concentration (see ESI). Compounds 1, $\mathbf{4}$ and $\mathbf{7}$ are the less active of the series, whereas the cyclohexyl- and cyclooctyl- derivatives are the ones that provoke a greater alteration of the $\mathrm{pH}$ inside the vesicles. This trend is similar to that found for the ISE assays.

We next decided to explore the ability of these compounds to facilitate anion transport in living cells using Fisher Rat Thyroid (FRT) cells expressing a variant of the iodide-sensitive Yellow Fluorescent Protein (YFP). ${ }^{15}$ Thus, FRT cells transfected with this YFP are incubated with the compounds (or DMSO, as control) at $37{ }^{\circ} \mathrm{C}$ for 30 minutes, and the emission baseline recorded for 2 seconds. Then, a sodium iodide aqueous solution (at $\mathrm{pH} 6.6$ or 7.3, depending on the experiment; see ESI) is injected and the emission measured for 20 seconds. The cellular internalisation of the iodide is signalled by the decay of the YFP's emission. Non-active anion transporters and control experiments with DMSO resulted in no internalisation of iodide and no changes in the observed fluorescence. The quenching rate $(Q R)$ at different concentrations of the compounds for both $\mathrm{pH}$ values was represented against such concentrations and the resulting curves were fitted to a first-order binding model. ${ }^{16}$

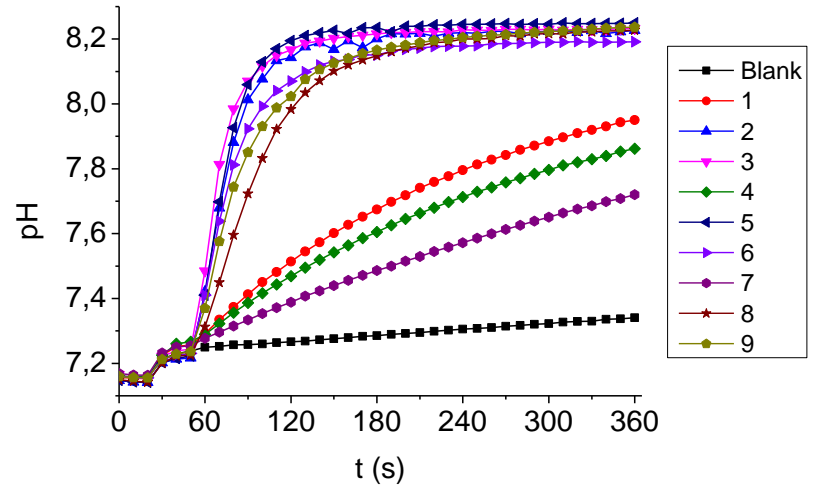

Fig. 3 Variation of pH upon addition of the studied compounds to 7:3 POPC:cholesterol vesicles ( $0.5 \mathrm{mM}$ POPC). Vesicles (loaded with $126.2 \mathrm{mM} \mathrm{NaNO}_{3}$ buffered at $\mathrm{pH} 7.2$ with $10 \mathrm{mM}$ phosphate, and containing $10 \mu \mathrm{M} \mathrm{HPTS}$; I.S. $150 \mathrm{mM}$ ) were suspended in a $\mathrm{NaNO}_{3}$ aqueous solution ( $126.2 \mathrm{mM} \mathrm{NaNO}_{3}$ buffered at $\mathrm{pH} 7.2$ with $10 \mathrm{mM}$ phosphate; I.S. 150 $\mathrm{mM})$. At $\mathrm{t}=30 \mathrm{~s}$ an aliquot of a $\mathrm{NaOH}$ solution $(11 \mu \mathrm{L}, 0.5 \mathrm{M})$ was added, and at $\mathrm{t}=60 \mathrm{~s}$ the anion carrier was added $(0.0005 \% \mathrm{~mol}$ carrier to lipid concentration). The blank is DMSO $(10 \mu \mathrm{L})$. Each trace represents the average of at least three trials, performed with three different batches of vesicles.

This fitting provides the maximum quenching rate ( $\mathrm{mQR}$ ), which is a direct indication of the activity of the compound as anion transporter; the higher its value, the more active the carrier is (see ESI for a detailed procedure and the plots). Calculated mQR values are displayed in Table 2 . The activity trend is in agreement with the previous results observed in liposomes. Thus, very limited activity was observed for the cyclopropylderivatives 1, 4 and 7, whereas cyclohexyl- and cyclooctylcompounds $\mathbf{2}, \mathbf{3}, \mathbf{5}, \mathbf{6}, \mathbf{8}$ and $\mathbf{9}$ display significant activity. The observed transport activity increases when the assays were performed at a slightly acidic external $\mathrm{pH}$. Both observations are evident in Fig. 4, where the QR values for compounds $\mathbf{4 , 5}$ and $\mathbf{6}$ are plotted against different concentrations of the compounds. This result is also in agreement with the demonstrated ability of these compounds to discharge $\mathrm{pH}$ gradients in liposomes and bodes well for potential applications in the case of cystic fibrosis, where an acidic airway surface liquid is a hallmark of the pathophysiology of this condition at the pulmonary level. For comparison purposes, it should be noted that the measured mQR of the activated wild type CFTR protein under these conditions is lower than $0.1 \mathrm{~s}^{-1} .17$

Table 2 Transport activities of compounds 1-9 in FRT cells at pH 6.6 and 7.3 (outer medium), expressed as $\mathrm{mQR}\left(\mathrm{s}^{-1}\right)$, and cell viability $\mathrm{IC}_{50}(\mu \mathrm{M})$ of such compounds in human lung (A549) and breast (MCF7) adenocarcinoma cell lines and in human mammary epithelial (MCF10A) cell lines.

\begin{tabular}{|c|c|c|c|c|c|}
\hline Comp. & $\begin{array}{c}\mathrm{mQR} \\
(\mathrm{pH} 6.6)\end{array}$ & $\begin{array}{c}\mathrm{mQR} \\
(\mathrm{pH} 7.3)\end{array}$ & $\begin{array}{c}\mathrm{IC}_{50} \\
(\mathrm{~A} 549)\end{array}$ & $\begin{array}{c}\mathrm{IC}_{50} \\
(\mathrm{MCF7})\end{array}$ & $\begin{array}{c}\mathrm{IC}_{50} \\
(\mathrm{MCF} 10 \mathrm{~A})\end{array}$ \\
\hline $\mathbf{1}$ & 0.07 & 0.02 & $41.1 \pm 16.9$ & $34.9 \pm 12.0$ & $23.5 \pm 9.0$ \\
\hline $\mathbf{2}$ & 0.33 & 0.09 & $7.3 \pm 1.6$ & $7.4 \pm 1.8$ & $6.2 \pm 1.2$ \\
\hline $\mathbf{3}$ & 0.32 & 0.16 & $7.1 \pm 1.1$ & $7.6 \pm 1.7$ & $3.7 \pm 1.7$ \\
\hline $\mathbf{4}$ & 0.02 & 0.01 & $43.6 \pm 11.8$ & $49.1 \pm 10.2$ & $51.4 \pm 17.7$ \\
\hline $\mathbf{5}$ & 0.33 & 0.12 & n.d. & n.d. & n.d. \\
\hline $\mathbf{6}$ & 0.21 & 0.23 & $7.2 \pm 0.5$ & $7.0 \pm 1.9$ & $4.8 \pm 2.5$ \\
\hline $\mathbf{7}$ & 0.02 & 0.02 & $41.7 \pm 14.8$ & $50.1 \pm 17.0$ & $34.4 \pm 8.6$ \\
\hline $\mathbf{8}$ & 0.37 & 0.29 & $3.5 \pm 1.1$ & $6.1 \pm 1.3$ & $10.7 \pm 2.2$ \\
\hline $\mathbf{9}$ & 0.28 & 0.21 & $5.9 \pm 1.1$ & $7.6 \pm 2.4$ & $6.5 \pm 1.3$ \\
\hline
\end{tabular}



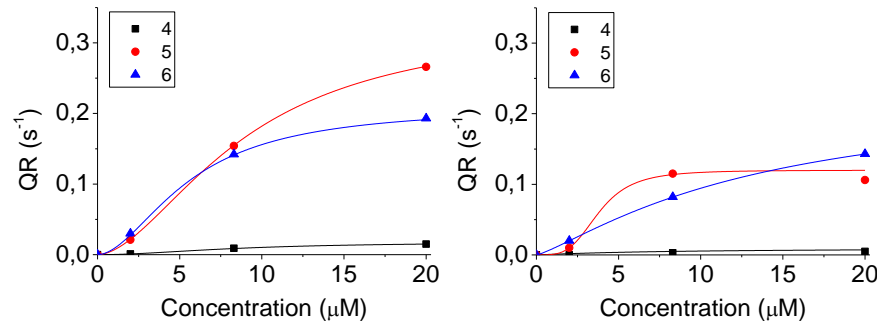

Fig. 4 Representation of the quenching rate $(Q R)$ at different concentrations of compounds $\mathbf{4}, \mathbf{5}$ and $\mathbf{6}$ at pH 6.6 (left) and 7.3 (right).

Finally, the cytotoxicity of these compounds was analysed. The concentration that provokes $50 \%$ growth inhibition $\left(\mathrm{IC}_{50}\right.$ values) was determined on human lung (A549) and breast (MCF7) adenocarcinoma cell lines, as well as human mammary epithelial (MCF10A) cell lines (Table 2). Compounds 2, 3, 5, 6, 8 and 9 display moderate cytotoxicities, with $\mathrm{IC}_{50}$ values ranging from 3.5 to $10.7 \mu \mathrm{M}$, whereas compounds $\mathbf{1}, \mathbf{4}$ and $\mathbf{7}$ are considerably less cytotoxic (from 23.5 to $51.4 \mu \mathrm{M}$ ). Little discrimination between normal and cancerous cell lines was observed. These results strongly suggest that the observed toxicity is related to the transmembrane transport ability of these compounds. On the other hand, very significant transport activity was observed in FRT cells for the active compounds at concentrations well below their $\mathrm{IC}_{50}$ values.

In summary, nine click-tambjamine compounds have been synthesised and characterised and their transmembrane anion transport activities in both model liposomes (POPC) and living cells investigated. Based on this design we have identified cyclohexyl- and cyclooctyl- derivatives which are remarkably active anion carriers in both vesicles and living cells. The suitability of the molecular design to produce and explore numerous compounds in an easy manner might constitute a good starting point for the design of a drug oriented to the treatment of anion-transport related diseases, such as cystic fibrosis.

Financial support from the European Union's Horizon 2020 research and innovation programme (TAT-CF project, grant agreement 667079), Instituto de Salud Carlos III (Grant PI18/00441) (co-funded by the European Regional Development Fund (ERDF), a way to build Europe) and "La Caixa" Foundation and Caja Burgos Foundation (CAIXAUBU004) is gratefully acknowledged. V. S.-C. and R. P.-T. also thank CERCA Programme/Generalitat de Catalunya for institutional support. The authors gratefully acknowledge Andrea Sancho-Medina and Víctor Arnáiz-Lozano for their contributions to transmembrane anion transport experiments and Paula Nadeu for her technical assistance.

\section{Conflicts of interest}

There are no conflicts to declare.

\section{Notes and references}

1 (a) N. Busschaert and P. A. Gale, Angew. Chem., Int. Ed., 2013, 52, 1374-1382; (b) P. A. Gale, J. T. Davis and R. Quesada, Chem. Soc. Rev., 2017, 46, 2497-2519.

2 (a) G. W. Gokel and S. Negin, Acc. Chem. Res., 2013, 46, 28242833; (b) M. M. Faul and B. E. Huff, Chem. Rev., 2000, 100, 2407-2474; (c) A. Huczynski, Bioorg. Med. Chem. Lett., 2012, 22, 7002-7010.

3 (a) P. A. Gale, E. N. W. Howe and X. Wu, Chem, 2016, 1, 351422; (b) H. Valkenier, O. Akrawi, P. Jurcek, K. Sleziakova, T. Lizal, K. Bartik and V. Sindelar, Chem, 2019, 5, 429-444.

4 (a) M. Tosolini, P. Pengo and P. Tecilla, Curr. Med. Chem., 2018 25, 3560-3576; (b) X.-H. Yu, X.-Q. Hong, Q.-C. Mao and W.-H. Chen, Eur. J. Med. Chem., 2019, 184, 111782.

5 (a) L. Tapia, Y. Pérez, M. Bolte, J. Casas, J. Solà, R. Quesada and I. Alfonso, Angew. Chem., Int. Ed., 2019, 58, 12465-12468; (b) S.-H. Park, S.-H. Park, E. N. W. Howe, J. Y. Hyun, L.-J. Chen, I. Hwang, G. Vargas-Zuñiga, N. Busschaert, P. A. Gale, J. L. Sessler and I. Shin, Chem, 2019, 5, 2079-2098; (c) L. A. Jowett, E. N. W. Howe, V. Soto-Cerrato, W. V. Rossom, R. Pérez-Tomás and P. A. Gale, Sci. Rep., 2017, 7, 9397.

6 (a) H. Li, H. Valkenier, A. G. Thorne, C. M. Dias, J. A. Cooper, M. Kieffer, N. Busschaert, P. A. Gale, D. N. Sheppard and A. P. Davis, Chem. Sci., 2019, 10, 9663-9672; (b) M. Fiore, C. Cossu, V. Capurro, C. Picco, A. Ludovico, M. Mielczarek, I. CarreiraBarral, E. Caci, D. Baroni, R. Quesada and O. Moran, Br. J. Pharmacol., 2019, 176, 1764-1779.

7 (a) H. Behera and N. Madhavan, J. Am. Chem. Soc., 2017, 139 12919-12922; (b) I. Carreira-Barral, C. Rumbo, M. Mielczarek, D. Alonso-Carrillo, E. Herran, M. Pastor, A. Del Pozo, M. García-Valverde and R. Quesada, Chem. Commun., 2019, 55, 10080-10083; (c) S. V. Shinde and P. Talukdar, Org. Biomol. Chem.,2019, 17, 4483-4490. S. B. Salunke, J. A. Malla and P. Talukdar, Angew. Chem., Int. Ed., 2019, 58, 5354-5358.

8 (a) X. Wu, E. N. W. Howe and P. A. Gale, Acc. Chem. Res., 2018, 51, 1870-1879; (b) Y. Yang, X. Wu, N. Busschaert, H. Furuta and P. A. Gale, Chem. Commun., 2017, 53, 9230-9233; (c) C. Cossu, M. Fiore, D. Baroni, V. Capurro, E. Caci, M. GarciaValverde, R. Quesada and O. Moran, Front. Pharmacol., 2018, 9, 852 .

9 (a) R. A. Davis, A. R. Carroll and R. J. Quinn, Aust. J. Chem., 2001, 54, 355-359; (b) A. J. Blackman and C. P. Li, Aust. J. Chem., 1994, 47, 1625-1629; (c) B. Carté and D. J. Faulkner, J. Org. Chem., 1983, 48, 2314-2318.

10 (a) Y. Hua and A. H. Flood, Chem. Soc. Rev., 2010, 39, 12621271; (c) S. Chen, S. Zhang, C. Bao, C. Wang, Q. Lin and L. Zhu, Chem. Commun., 2016, 52, 13132-13135.

11 (a) P. Thordarson, Chem. Soc. Rev., 2011, 40, 1305-1323; (b) www.supramolecular.org (last access: January 2020).

12 L. A. Jowett and P. A. Gale, Supramol. Chem., 2019, 31, 297312.

13 N. J. Knight, E. Hernando, C. J. E. Haynes, N. Busschaert, H. J. Clarke, K. Takimoto, M. García-Valverde, J. G. Frey, R. Quesada and P. A. Gale, Chem. Sci., 2016, 7, 1600-1608.

14 S. Matile and N. Sakai, Analytical Methods in Supramolecular Chemistry, ed. C. A. Schalley, Wiley-VCH, Weinheim, 2012, pp. 711-742.

15 E. Caci, A. Caputo, A. Hinzpeter, N. Arous, P. Fanen, N. Sonawane, A. S. Verkman, R. Ravazzolo, O. Zegarra-Moran and L. J. V. Galietta, Biochem. J., 2008, 413, 135-142.

16 T. P. Kenakin, A pharmacology primer: theory, applications and methods, Elsevier/Academic Press, Amsterdam, 2010.

17 E. Hernando, V. Capurro, C. Cossu, M. Fiore, M. GarcíaValverde, V. Soto-Cerrato, R. Pérez-Tomás, O. Moran, O. Zegarra-Moran and R. Quesada, Sci. Rep., 2018, 8, 2608. 